Chronic Obstructive Pulmonary Diseases: Journal of the COPD Foundation

\author{
Original Research
}

\title{
Corticosteroid Dosing and Glucose Levels in COPD Patients Are Not Associated with Increased Readmissions
}

\author{
Meghan McGraw, MD ${ }^{1}$ Heath D. White, DO, MS ${ }^{1}$ Kiumars Zolfaghari, MS ${ }^{1}$ \\ Angela Hochhalter, $\mathrm{PhD}^{1}$ Alejandro Arroliga, $\mathrm{MD}^{1}$ Carl Boethel, $\mathrm{MD}^{1}$
}

\section{Abstract}

Introduction: Hospital admissions and readmissions for chronic obstructive pulmonary disease (COPD) exacerbations are associated with increased mortality and higher cost. The management of exacerbations with a shortened course of systemic corticosteroids has similar efficacy as compared to longer steroid courses, but actual overall steroid dose given is still variable. The outcomes associated with steroid side effects, such as hyperglycemia, need further evaluation. We hypothesized that the use of higher doses of corticosteroids, and the subsequent hyperglycemia, contributes to readmission.

Methods: This is a retrospective study at a tertiary care referral center in central Texas between February 2014 and July 2016. Daily corticosteroid dose, blood glucose levels, and readmission rates at 30 and 31-90 days were recorded. Sample characteristics are described using descriptive statistics. A chi-square test or student's $t$-test were used to test for associations in bivariate comparisons. Multivariable logistic regression assessed the association between readmission rate and demographic and clinical characteristics.

Results: There were 1120 patients admitted for COPD exacerbation between February 2014 and July 2016. A total of $57 \%$ were female, mean age was 69 years (standard deviation [SD] 12), and average body mass index (BMI) was 29.4 (SD 9.8). Of the total, 349 (31\%) had diabetes prior to admission. The 30-day readmission rate was $16 \%$, and the readmission rate from $31-90$ days was $14 \%$. The average prednisone equivalent dose per day during hospitalization was $86 \mathrm{mg}$ (SD 52). A multivariable logistic regression model did not show any significant association between readmission and average daily glucose, high maximum glucose $(>180 \mathrm{mg} / \mathrm{dL}$ on any reading), or prednisone equivalent administered per day.

Conclusion: Corticosteroid dose and hyperglycemia were not associated with an increased 30-day or 31-90-day readmission rate after $\mathrm{COPD}$ exacerbation discharge. In addition, using higher doses of corticosteroids instead of standard-of-care (prednisone $40 \mathrm{mg}$ per day for a 5-day period) did not appear to affect the readmission rate in this cohort.

\footnotetext{
Abbreviations: chronic obstructive pulmonary disease, COPD; standard deviation, SD; body mass index, BMI; analysis of variance, ANOVA; odds ratio, OR

Funding Support: none.

Date of Acceptance: October 22, 2020 | Published Online Date: November 19, 2020

Citation: McGraw M, White HD, Boethel C, Zolfaghari K, Hochhalter A, Arroliga A. Corticosteroid dosing and glucose levels in COPD patients are not associated with increased readmissions. Chronic Obstr Pulm Dis. 2021;8(1):117-123. doi: https://doi.org/10.15326/ jcopdf.2020.0172
}

1 Division of Pulmonary, Critical Care and Sleep Medicine, Baylor

Scott and White Health, Temple, Texas, United States 


\section{Address correspondence to:}

Carl Boethel, MD

Department of Internal Medicine

Division of Pulmonary, Critical Care \& Sleep Medicine

Scott \& White Medical Center

Texas A \& M University

2401 S. 31st Street

Temple, TX 76508

Phone: 254-724-9887

Email: Carl.Boethel@BSWHealth.org

\section{Keywords:}

COPD; chronic obstructive pulmonary disease; readmission; corticosteroid dosing; hyperglycemia

\section{Note: These findings were partially presented at the American Thoracic Society International Conference in 2018}

\section{Introduction}

Acute exacerbations of chronic obstructive pulmonary disease (COPD) lead to increased mortality and morbidity, and frequently require hospitalization. ${ }^{1}$ The greatest risk factor for future hospitalization for COPD exacerbation is a history of hospitalization for exacerbation, ${ }^{1}$ so optimization of care during the hospital stay is critical to help reduce the burden of readmissions.

One of the mainstay treatments used in patients admitted to the hospital is systemic corticosteroids, both oral and parenteral. Early investigations into corticosteroid use for COPD exacerbation supported using corticosteroids over placebo to shorten a hospital stay as well as reduce rate of treatment failure (death, readmission, intubation) at 30 and 90 days, though it was noted that the patients who received glucocorticoid therapy were more likely to have hyperglycemia requiring therapy than those who received the placebo. ${ }^{2,3}$ In recent years, there has been a trend toward reducing the amount of corticosteroids administered to patients, with the finding that lower doses can still adequately treat the patient. The Reduction in the Use of Corticosteroids in Exacerbated COPD (REDUCE) trial found that a 5day course of oral corticosteroids was noninferior to a 7-14 day course, and that a 5- day course of treatment was associated with overall shorter hospital length of stay. $^{4}$

Providing the lowest corticosteroid dose can decrease the risk of complications including hyperglycemia, osteoporosis, fractures, obesity, and susceptibility to infections, among others. ${ }^{5}$ Moreover, it is estimated that $28 \%$ of patients admitted for COPD exacerbation suffer from diabetes. ${ }^{6}$ Although the current literature recommends prednisone $40 \mathrm{mg}$ per day for a 5-day period, ${ }^{4}$ actual dose given and length of treatment are highly variable.

Given the known risk of hyperglycemia with corticosteroid use, we hypothesized that higher doses of corticosteroids will lead to increased readmissions, due to complications of hyperglycemia. The objective of this study was to assess rates of corticosteroid overuse in hospitalized COPD exacerbation patients admitted to a tertiary care referral center in central Texas, and to determine if corticosteroid exposure and average blood glucose had any effect on hospital readmission.

\section{Methods}

\section{Study Design and Data Collection}

A retrospective study of patients above 18 years old admitted for COPD exacerbation was conducted at a tertriary care referral center in central Texas between February 2014 and July 2016. A COPD exacerbation was defined in 2 ways based on Center for Medicare and Medicaid Services guidelines (Supplement A in the online supplement). Data collection included demographics, age, sex, body mass index (BMI), daily corticosteroid dosing, average daily blood glucose level, emergency department admission, length of hospitalization, and discharge disposition. The primary outcomes studied were readmission rates at 30 and 31-90 days. Prednisone equivalent dosage was calculated for each different type of corticosteroid administered per individual during hospitalization. ${ }^{7}$ The average daily glucose was determined as the mean of glucose levels per day during hospitalization and high maximum glucose was recorded as an indicator of whether the patient had any glucose level reading over $180 \mathrm{mg} / \mathrm{dL}$ during hospitalization. Discharge disposition was grouped into 4 categories: home, home with home health, post-hospital facility, and other (court/law enforcement, home with hospice, inpatient hospice, and left against medical advice).

\section{Statistical Analysis}

Sample characteristics are described using descriptive statistics. Frequencies and percentages 
are used to describe categorical variables. Means and standard deviations (or medians and ranges where appropriate) are used to describe continuous variables. A chi-square test (or Fisher's exact test where appropriate) and student's $t$-test (or their nonparametric equivalents) were used to assess outcomes among different patient groups. An analysis of variance (ANOVA) model (or Kruskal-Wallis test when appropriate) was used to test for differences in continuous variables between the $3+$ groups. The posthoc Tukey's test was used for pairwise comparisons when the ANOVA test showed a statistically significant result. Multivariable logistic regression assessed the association between readmission rate, glucose, and prednisone equivalent dosage adjusting for age, sex, BMI, history of diabetes, emergency department admission, and discharge disposition. The regression model variables were selected to control for potential confounding factors that were of interest. The average daily glucose and high maximum glucose were used in separate regression models due to the high correlation. A subgroup analysis of this study was conducted which considered only patients carrying a diagnosis of diabetes in the year prior to their first COPD admission.

All analyses were performed using SAS, Version 9.4 (SAS Institute, Cary, North Carolina). Research was approved by the local institutional review board (protocol number 160323), and the need for consent was waived, due to the retrospective nature of the study.

\section{Results}

\section{Patient Characteristics}

A total of 1120 inidividuals were included in this study. The mean age was 69.2 years old (SD 11.6), average BMI was 29.4 (SD 9.8), and the majority were female (57\%). The median for hospital length of stay was 3 days (range 1-35) and 89\% were admitted through the emergency department. Of the total, 349 (31\%) had diabetes prior to admission. The average prednisone equivalent dose per day was $86.0 \mathrm{mg}$ (SD 52.1). Guideline-based dosing of prednisone equivalent $40 \mathrm{mg}$ per day was seen in 201 patients (18\%).

The average daily glucose level was $151.0 \mathrm{mg} / \mathrm{dL}$ (SD 52.1). Only 38\% had an average glucose of less than $120 \mathrm{mg} / \mathrm{dL}$ during their stay. Another $42 \%$ had averages between $120 \mathrm{mg} / \mathrm{dL}$ and $180 \mathrm{mg} / \mathrm{dL}$, and the rest had an average above $180 \mathrm{mg} / \mathrm{dL}$. There were 446 patients (40\%) with high maximum glucose ( $>180 \mathrm{mg} / \mathrm{dL}$ on any reading) (Table 1 ). Patients with diabetes prior to admission were the majority of the high maximum glucose group at $76 \%$ (Table 2). Patients with an average daily glucose $<120 \mathrm{mg} / \mathrm{dL}$ received less prednisone equivalent compared to those $>120 \mathrm{mg} / \mathrm{dL}(77.4 \mathrm{mg}$ versus $90.9 \mathrm{mg}, p<0.001)$.

\section{Outcomes}

The 30-day and 31-90-day readmission rates were $16 \%$ and $14 \%$ respectively and in-hospital mortality rate was $1.5 \%$. In decreasing order, patients were

\section{Table 1. Overall Demographics and Outcomes}

\begin{tabular}{|c|c|}
\hline & $\begin{array}{c}\text { Overall } \\
\text { Demographics } \\
(\mathrm{N}=1120) \\
\text { Mean (SD), } \mathrm{N}(\%), \\
\text { Median (min-max) }\end{array}$ \\
\hline Age & $69.2(11.6)$ \\
\hline Female & $638(57 \%)$ \\
\hline BMI & $29.4(9.8)$ \\
\hline Underweight (BMI <18.5) & $102(9 \%)$ \\
\hline Normal $(18.5 \leq \mathrm{BMI}<25)$ & $330(30 \%)$ \\
\hline Overweight $(25 \leq \mathrm{BMI}<30)$ & $237(21 \%)$ \\
\hline Obese (BMI >30) & $451(40 \%)$ \\
\hline Diabetes Diagnosis & $349(31 \%)$ \\
\hline Emergency Department Admission & $997(89 \%)$ \\
\hline & $\begin{array}{c}\text { Overall } \\
\text { Outcomes }\end{array}$ \\
\hline Hospitalization Length & $3(1-35)$ \\
\hline 30-Day Readmission & $181(16 \%)$ \\
\hline 31-90-Day Readmission & 159 (14\%) \\
\hline \multicolumn{2}{|l|}{ Discharge Disposition } \\
\hline Home & $702(63 \%)$ \\
\hline Home with home health & $216(19 \%)$ \\
\hline Post-hospital facility & $147(13 \%)$ \\
\hline Other & $55(5 \%)$ \\
\hline Average Daily Prednisone Equivalent & $85.8(52.1)$ \\
\hline Average Daily Glucose Level & $151(52.1)$ \\
\hline High Maximum Glucose ${ }^{a}$ & $446(40 \%)$ \\
\hline In-hospital Mortality & $17(1.5 \%)$ \\
\hline
\end{tabular}

${ }^{a}$ Number of patients with any glucose level reading over $180 \mathrm{mg} / \mathrm{dL}$ during hospitalization.

${ }^{b}$ Number of patients who died during hospitalization

$\mathrm{SD}=$ standard deviation; $\mathrm{BMI}=$ body mass index 


\section{Table 2. Patient With Diabetes Demographics and Outcomes Comparison}

\begin{tabular}{|c|c|c|c|}
\hline & \multicolumn{2}{|c|}{ Patient with Patient without } & \multirow[t]{2}{*}{$P$-value } \\
\hline & $\begin{array}{c}\text { Diabetes } \\
(\mathrm{N}=349)\end{array}$ & $\begin{array}{l}\text { Diabetes } \\
(\mathrm{N}=771)\end{array}$ & \\
\hline & \multicolumn{3}{|c|}{ Mean (SD), N(\%), Median (min-max) } \\
\hline Age & $69.7(11.0)$ & $69.0(11.9)$ & 0.2 \\
\hline Female & $208(60 \%)$ & 429 (56\%) & 0.2 \\
\hline \multirow[t]{2}{*}{ BMI } & $34.2(10.3)$ & $27.2(8.7)$ & $<0.001^{\mathrm{a}}$ \\
\hline & \multicolumn{3}{|c|}{ Overall Outcomes } \\
\hline Hospitalization length (days) & $3(1-19)$ & $3(0-35)$ & 0.5 \\
\hline 30-day Readmission & $69(20 \%)$ & $112(15 \%)$ & $0.03^{b}$ \\
\hline 31-90-day Readmission & $55(16 \%)$ & $104(14 \%)$ & 0.3 \\
\hline Emergency Department Admission & $315(90 \%)$ & $682(88 \%)$ & 0.4 \\
\hline \multicolumn{3}{|l|}{ Discharge Disposition } & \multirow[t]{5}{*}{0.6} \\
\hline Home & $210(60 \%)$ & $492(64 \%)$ & \\
\hline Home with home health & $74(21 \%)$ & $142(18 \%)$ & \\
\hline Post hospital facility & $49(14 \%)$ & $98(13 \%)$ & \\
\hline Other & $16(5 \%)$ & $39(5 \%)$ & \\
\hline Average Daily Prednisone Equivalent & $84.2(55.0)$ & $86.5(50.7)$ & 0.2 \\
\hline Average Daily Glucose Level & $197.7(63.0)$ & $129.9(26.8)$ & $<0.001^{\mathrm{a}}$ \\
\hline High Maximum Glucose & $266(76 \%)$ & $180(23 \%)$ & $<0.001^{\mathrm{a}}$ \\
\hline In-hospital Mortality & $5(1.4 \%)$ & $12(1.6 \%)$ & 0.8 \\
\hline $\begin{array}{l}{ }^{a} p<0.001 \\
{ }^{b} p<0.05\end{array}$ & & & \\
\hline
\end{tabular}

$\mathrm{SD}=$ standard deviation; $\mathrm{BMI}=$ body mass index

discharged to home (63\%), home with home health (19\%), post-hospital facility (13\%), and other locations (5\%) (Table 1).

Prednisone equivalent dosage was similar for those discharged to a post-hospital facility $(86.5 \mathrm{mg}$ daily) and those discharged to home with or without home health (84.0mg daily). Patients discharged to home with home health or a post-hospital facility were more likely to be readmitted within 30 days in comparison to those discharged home without home health (unadjusted odds ratio $[\mathrm{OR}]=1.60,95 \% \mathrm{CI}$ $[1.15,2.23], p<0.01)$.

Average daily glucose and guideline-based dosing of prednisone equivalent $40 \mathrm{mg}$ per day were not found to be associated with 30-day or 31-90-day readmission rates. However, 31-90- day readmission had a borderline significant association with high maximum glucose (unadjusted $\mathrm{OR}=1.37,95 \% \mathrm{CI}$ $[0.98,1.93], p=0.07)$.

In the multivariable logistic regression (Table 3 ), the odds of a 30-day readmission for the obese group (BMI>30) was lower than the normal group
(18.5 $\leq \mathrm{BMI}<25)$ (adjusted $\mathrm{OR}=0.56,95 \%$ CI $[0.37,0.86], p<0.05)$ and the odds of readmission for patients discharged to home with home health (adjusted $\mathrm{OR}=1.68,95 \%$ CI $[.12,2.50], p<0.05)$ or post-hospital facility (adjusted $\mathrm{OR}=1.64$, 95\% CI [1.02, 2.64], $p<0.05)$ was higher than those discharged to home without help. The regression models did not show any significant associations between 30-day readmission and average daily glucose, high maximum glucose, or prednisone equivalents per day after controlling for potential confounding factors. In accordance with the unadjusted model, the risk of readmission at 31-90 days had a borderline significant association with high maximum glucose (adjusted $\mathrm{OR}=1.44,95 \%$ CI [0.97, 2.14], $p=0.07)$ as demonstrated in Table 4.

\section{Subanalysis}

A subanalysis was conducted on 349 individuals with a diagnosis of diabetes. This subgroup of patients had a higher BMI (34.2 versus. 27.2, $p<0.001$ ) and average daily glucose level (197.7 versus $129.9, p<0.001)$ in comparison to the nondiabetic group. Also, high maximum glucose was prevailing $(76 \%)$ in this subgroup of patients. The 30 -day readmission rate was higher among patients with diabetes in comparison to others $(20 \%$ versus $15 \%, p=0.02)$. The hospital length of stay, emergency department admission rate, average prednisone equivalent, 31-90-day readmission rate, and discharge disposition were similar to the non-diabetic group (Table 2). Both unadjusted and adjusted models did not show any association between 30-day or 31-90-day readmission rates and glucose levels or prednisone equivalent doses in this specific group of individuals.

\section{Discussion}

We found that guideline discordant dosing of corticosteroids in the treatment of COPD exacerbation did not impact 30-day or 31-90-day readmission rates after discharge from the hospital. Additionally, average glucose level during the initial 


\section{Table 3. 30-Day Readmission Multivariable Logistic Regression}

\begin{tabular}{|c|c|c|c|c|}
\hline Variable & $\begin{array}{l}\text { Odds } \\
\text { Ratio }\end{array}$ & Confide & Limits & $P$-value \\
\hline Age & 0.98 & 0.84 & 1.14 & 0.8 \\
\hline Female & 0.86 & 0.62 & 1.19 & 0.4 \\
\hline Underweight $(\mathrm{BMI}<18.5)$ & 0.56 & 0.28 & 1.10 & $0.09^{\mathrm{a}}$ \\
\hline Overweight $(25 \leq \mathrm{BMI}<30)$ & 0.84 & 0.54 & 1.30 & 0.4 \\
\hline Obese $(\mathrm{BMI}>30)$ & 0.56 & 0.37 & 0.86 & $0.007^{\mathrm{b}}$ \\
\hline History of Diabetes & 1.79 & 1.17 & 2.75 & $0.008^{\mathrm{b}}$ \\
\hline $120<$ Glucose Average $<180$ & 1.09 & 0.74 & 1.59 & 0.6 \\
\hline $180<$ Glucose Average & 0.84 & 0.48 & 1.47 & 0.5 \\
\hline Prednisone Equivalent & 1.02 & 0.99 & 1.05 & 0.2 \\
\hline Discharge to Home Health & 1.68 & 1.12 & 2.50 & $0.01^{\mathrm{b}}$ \\
\hline Discharge to Post-Hospital Facility & 1.64 & 1.02 & 2.64 & $0.04^{\mathrm{b}}$ \\
\hline Discharge to Other & 0.31 & 0.09 & 1.04 & $0.06^{\mathrm{a}}$ \\
\hline Emergency Department Admission & 1.03 & 0.61 & 1.75 & 0.9 \\
\hline
\end{tabular}

${ }^{\mathrm{a}} p<0.1$

${ }^{\mathrm{b}} p<0.05$

$\mathrm{BMI}=$ body mass index

\section{Table 4. 31-90-Day Readmission Multivariable Logistic Regression}

\begin{tabular}{|l|c|c|c|c}
\hline Variable & Odds & \multicolumn{2}{|c}{$95 \%$} & P-value \\
& Ratio & Confidence Limits & \\
\hline Age & 0.93 & 0.79 & 1.09 & 0.4 \\
\hline Female & 1.17 & 0.82 & 1.66 & 0.4 \\
\hline Underweight $(\mathrm{BMI}<18.5)$ & 1.56 & 0.83 & 2.92 & 0.2 \\
\hline Overweight $(25 \leq \mathrm{BMI}<30)$ & 1.33 & 0.82 & 2.18 & 0.3 \\
\hline Obese (BMI>30) & 1.04 & 0.66 & 1.64 & 0.8 \\
\hline History of Diabetes & 1.01 & 0.66 & 1.55 & 0.9 \\
\hline High Maximum Glucose & 1.44 & 0.97 & 2.14 & $0.07^{\mathrm{b}}$ \\
\hline Prednisone Equivalent & 0.99 & 0.96 & 1.03 & 0.7 \\
\hline Discharge to Home Health & 1.01 & 0.65 & 1.57 & 0.9 \\
\hline Discharge to Post-Hospital Facility & 1.14 & 0.68 & 1.92 & 0.6 \\
\hline Discharge to Other & 0.11 & 0.02 & 0.84 & $0.03^{\mathrm{c}}$ \\
\hline Emergency Department Admission & 2.24 & 1.10 & 4.55 & 0.02 \\
\hline
\end{tabular}

${ }^{a}$ High maximum glucose replaced average daily glucose

${ }^{\mathrm{b}} p<0.1$

${ }^{c} p<0.05$

BMI=body mass index

hospital stay did not impact 30- day or 31-90-day readmission rates after discharge. These findings suggest that strict adherence to guideline-based corticosteroid dosing during hospitalization for COPD exacerbation may not impact the patient's risk of readmission in the immediate or 3-month periods and this heterogeneity in steroid prescribing practice is consistent with other literature. We did find that patients discharged home with home health or a post hospital facility were more likely to be readmitted within 30 days compared to those discharged home without home health (21\% versus $14 \%, p<0.01$ ), which may be a major factor to total cost of care.

Our findings do not give license to use of higher doses of steroids, as this study was not designed to evaluate the effectiveness of current corticosteroid recommendations. Risk of hyperglycemia from higher doses of corticosteroids should continue to be a consideration for clinicians. Umpierrez et al showed that patients with new onset hyperglycemia on admission had increased mortality and length of stay compared to those with normoglycemia on admission, ${ }^{8}$ though glucose levels at readmission was not studied in our data. Additionally, new onset diabetes has been observed to occur in up to $46 \%$ of patients after initiation of corticosteroid therapy. ${ }^{9}$ Furthermore, Blackburn et al found that the risk of diabetes was even higher in the elderly population when initiated on a corticosteroid. $^{10}$

We did perform a subgroup analysis consisting of those carrying a diagnosis of diabetes prior to their initial admission, but the analysis did not show any significant trend regarding readmission rates. Breakey et al showed similar outcomes when they found that glucocorticoid use increased the risk of hyperglycemia in admitted patients with respiratory diseases except in those previously carrying a diagnosis of diabetes. ${ }^{11}$ This is somewhat counterintuitive, as one would expect those who already have insulin resistance and depletion would be more likely to develop hyperglycemia from a trigger. It is possible that glucose levels during admission are more aggressively managed in those who have been identified to clinicians as diabetics.

Our current study has design lmitations and the findings of this study should be interpreted within the appropriate context. The study was retrospective which should be considered before generalization. Another limitation is the lack of protocolized management of COPD exacerbation and variability in steroid administration, although order sets are 
available to encourage standardization of care. Finally, data regarding past history related to COPD and the severity were not available secondary to study design.

Additional research is needed to understand if, and how, in-hospital treatment of COPD exacerbation impacts functional status, and health, after discharge.

\section{Conclusion}

We conclude that guideline discordant dosing of corticosteroids and the average daily glucose level in the treatment of COPD exacerbation did not impact 30-day or 31-90-day readmission rates after discharge from the hospital.

\section{Acknowledgements}

Author contributions: Drs. McGraw, White, Hochhalter, Arroliga and Boethel contributed to the study design, manuscript writing, and editing. Mr. Zolfaghari contributed to the study design, manuscript writing and editing and data analysis.

\section{Declaration of Interest}

The authors have no conflicts of interest to disclose. 


\section{References}

1. Mullerova H, Maselli DJ, Locantore N, et al. Hospitalized exacerbations of COPD: risk factors and outcomes in the ECLIPSE cohort. Chest. 2015;147(4):999-1007.

doi: https://doi.org/10.1378/chest.14-0655

2. Niewoehner DE, Erbland ML, Deupree RH, et al. (1999). Effect of systemic glucocorticoids on exacerbations of chronic obstructive pulmonary disease. Department of Veterans Affairs Cooperative Study Group. New Eng J Med.1999;340(25):1941-1947.

doi: https://doi.org/10.1056/NEJM199906243402502

3. Lindenauer PK, Pekow PS, Lahti MC, Lee Y, Benjamin EM, Rothberg MB. Association of corticosteroid dose and route of administration with risk of treatment failure in acute exacerbation of chronic obstructive pulmonary disease. JAMA. 2010;303:2359-2367.

doi: https://doi.org/10.1001/jama.2010.796

4. Leuppi JD, Schuetz P, Bingisser R, et al. Short-term versus conventional term glucocorticoid therapy in acute exacerbations of chronic obstructive pulmonary disease. The REDUCE randomized clinical trial. JAMA. 2013;309(21):2223-2231.

doi: https://doi.org/ 10.1186/ISRCTN19646069

5. Manson SC, Brown RE, Cerulli A, Vidaurre CF. The cumulative burden of oral corticosteroid side effects and the economic implications of steroid use. Respir Med. 2009;103(7):975-994.

doi: https://doi.org/10.1016/j.rmed.2009.01.003

6. Almagro P, Cabrera FJ, Diez J, et al. Comorbidities and short-term prognosis in patients hospitalized for acute exacerbation of COPD. Chest. 2012;142(5):1126-1133.

doi: https://doi.org/10.1378/chest.11-2413

7. Liu D, Ahmet A, Ward L, et al. A practical guide to the monitoring and management of complications of systemic corticosteroid therapy. Allergy Asthma Clin Immunol. 2013;9(1):30.

doi: https://doi.org/10.1186/1710-1492-9-30

8. Umpierrez GE, Isaacs S, Bazargan N. Hyperglycemia: an independent marker of in-hospital mortality in patients with undiagnosed diabetes. J Clin Endocrinol Metab. 2002;87(3):978-982.

doi: https://doi.org/10.1210/jc.87.3.978

9. Braithwaite SS, Barr WG, Rahman A, Quddusi S. Managing diabetes during glucocorticoid therapy. Postgrad Med. 1998;104(5):163-176. doi: https://doi.org/10.3810/pgm.1998.11.426

10. Blackburn D, Hux J, Mamdani M. Quantification of the risk of corticosteroid-induced diabetes mellitus among the elderly. J Gen Intern Med. 2002;(17(9):717-720.

doi: https://doi.org/10.1046/j.1525-1497.2002.10649.x

11. Breakey S, Sharp SJ, Adler AI, Challis BG. Glucocorticoid-induced hyperglycaemia in respiratory disease: a systematic review and metaanalysis. Diabetes Obes Metab. 2016;18(12):1274-1278.

doi: https://doi.org/10.1111/dom.12739 